\title{
Faktor yang Berhubungan dengan Keberhasilan ASI Eksklusif
}

\author{
Rokhmah Ayu Suliasih,* Dwiyanti Puspitasari, ${ }^{* *}$ Dhasih Afiat DP*** \\ *Program Studi Pendidikan Bidan Fakultas Kedokteran Universitas Airlangga, Surabaya \\ ${ }^{*}$ Departemen SMF Ilmu Kesehatan Anak RSUD dr Soetomo/Fakultas Kedokteran Universitas Airlangga, Surabaya \\ ${ }^{* * *}$ Program Studi Pendidikan Bidan Fakultas Kedokteran Universitas Airlangga, Surabaya
}

Latar belakang. Pemberian ASI eksklusif (AE) merupakan intervensi yang efektif untuk mencegah penyakit metabolik dan permasalahan kesehatan anak. Data Survey Demografi dan Kesehatan Indonesia (SDKI) tahun 2012 dan 2016 menunjukkan angka ASI eksklusif di Jawa Timur cenderung turun. Faktor yang memengaruhi pemberian AE meliputi faktor pemudah, pendukung, dan pendorong. Tujuan. Mengetahui hubungan antara faktor pemudah (pengetahuan tentang tanda kecukupan ASI, karakteristik sosiodemografi), pendukung (cara persalinan, Inisiasi menyusu dini, paritas ibu), dan pendorong (tenaga kesehatan, keluarga, dan media) dengan keberhasilan AE.

Metode. Penelitian potong lintang analitik melalui pengisian kuesioner oleh ibu yang memiliki anak berusia 6-11 bulan yang datang ke Posyandu atau Puskesmas Simomulyo dan Manukan Kulon, Surabaya pada bulan Maret-April 2018. Data hasil pengisian kuesioner dianalisis statistik menggunakan uji Kai kuadrat dan regresi logistik, dengan confidence interval (CI) 95\%.

Hasil. Didapatkan proporsi AE 61\% dari sejumlah $82 \mathrm{ibu}$, semua ibu pernah melihat iklan formula, dan alasan terbesar (53,1\%) ibu tidak memberikan AE karena khawatir ASI tidak cukup. Usia ibu $(\mathrm{p}=0,020)$, pekerjaan $(\mathrm{p}=0,003)$, pendidikan terakhir $(\mathrm{p}=0,030)$, dan riwayat keberhasilan pemberian AE pada anak yang sebelumnya $(\mathrm{p}=0,032)$ berhubungan dengan AE.

Kesimpulan. Ibu yang berusia 25-30 tahun, berpendidikan tinggi, memiliki riwayat keberhasilan AE, dan tidak bekerja dapat memengaruhi keberhasilan pemberian AE. Sari Pediatri 2019;20(6):375-81

Kata kunci: ASI eksklusif, karakteristik ibu, tanda kecukupan ASI

\section{The Successful Exclusive Breastfeeding and Associated Factors}

\author{
Rokhmah Ayu Suliasih, ${ }^{*}$ Dwiyanti Puspitasari, ${ }^{* *}$ Dhasih Afiat DP***
}

Background. Exclusive breastfeeding (EB) was the most effective intervention for preventing metabolic disease and have an important role in children's health and growth. But in East Java the practice is decreased from 2012-2016. Predisposing, enabling, and reinforcing factors which influencing EB.

Objective. This study aimed at determining the breastfeeding practices, examining mother's knowledge about the sign sufficient breastmilk, sociodemographic characteristics, and other EB factors including the type of delivery, early initiation of BF, parity, family and health workers support.

Method. This was a cross-sectional study that employed a structured questionnaire to collect data among mothers of a healthy infant aged 6-11 months, attending Simomulyo and Manukan Kulon public health services in Surabaya from March to April 2018. Analyzed using chi-square and multiple logistic regression were described using $95 \%$ confidence intervals (CI).

Result. Collected 82 mothers. EB was practiced by $61 \%$ of mothers. All mother has seen formula feeding advertisement, cessation EB because worried that breast milk only is not enough was $53.1 \%$. Mother's age $(p=0,020)$, occupation $(p=0,003)$, formal education $(\mathrm{p}=0,030)$, and $\mathrm{EB}$ experiences $(\mathrm{p}=0,032)$ was correlated to $\mathrm{EB}$.

Conclusion. Mothers aged 25-30 years, does not work, highly educated, and experienced EB mothers are influencing EB. Sari Pediatri 2019;20(6):375-81

Keywords: exclusive breastfeeding, mother's characteristic, sign of breastmilk sufficiency

Alamat korespondensi: Dwiyanti Puspitasari. Departemen SMF Ilmu Kesehatan Anak RSUD Dr Soetomo/Fakultas Kedokteran Universitas Airlangga, Surabaya. RSUD Dr. SoetomoLantai 3, Jl. Mayjend Prof. Dr. Moestopo 6-8, Surabaya 60286. Email: dwiyanti-p@fk.unair.ac.id 
$\mathrm{P}$

masalahan gizi balita di Indonesia cenderakhir, peningkatan tersebut terjadi pad julah kejadian balita pendek atau stunting dan jumlah balita gemuk. Beberapa studi menyataka bahwa ASI dapat mencegah berbagai masalah kesehatan tersebut. Pemberian ASI eksklusif dapat mencegah bayi dari penyakit gastrointestinal dan gangguan pertumbuhan. ${ }^{1,2}$ Selain itu, ASI eksklusif juga dapa menurunkan risiko obesitas pada anak dan risiko penyakit diabetes pada ibu dan bayi ${ }^{3-5}$ Pada studi lain, pemberian ASI eksklusif dapat menurunkan inside DM dan masalah paru-paru, serta meningkaten IQ

Pada negara berkembang, cakupan ASI eksklusif

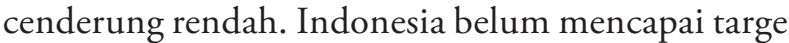
ASI eksklusif nasional. Jawa Timur khususnya belum mencapai target tersebut. ${ }^{7}$ Beberapa alasan ibu berhenti menyusui sangat kompleks dan dipengaruhi oleh sosiodemografi, biofisik, dan faktor psikososial. Saat ini, alasan utama ibu menghentikan pemberian ASI atau makanan tambahan sebelum waktunya adalah karena persepsi ketidakcukupan ASI. Perseps ketidakcukupan ASI pada ibu dapat mengakibatkan ibu kurang percaya diri. Hal tersebut termasuk dalam faktor psikososial, beberapa bentuk faktor telah terbukti memengaruhi durasi menyusui. Penelitian ini bertujuan untuk menganalisis hubungan antara pengetahuan ibu tentang tand kecukupan ASI, beserta faks lainga dengan keberhasilan pemberian ASI eksklusif. Kemudian menganalisis interaksi antar faktor keberhasilan pemberian ASI eksklusif.

\section{Metode}

Rancangan penelitian ini adalah potong lintang analitik. Pengambilan sampel dilakukan melalui pengisian kuesioner oleh ibu yang memiliki bayi usia 6-11 bulan pada bulan Maret-April 2018 di Posyandu atau Puskesmas Simomulyo dan Manukan Kulon Surabaya. Kriteria inklusi adalah bayi yang tidak memiliki cacat bawaan, bayi dengan berat badan lahir normal dan ibu yang berdomisili di wilayah keria Puskesmas Simomulyo atau Puskesmas Manukan Kulon Surabaya. Kriteria eksklusi adalah bayi dal kondisi sakit dan ibu yang memiliki riwayt opera payudara.
Dilakukan pengambilan data melalui kuesioner ang mengkaji pengetahuan ibu tentang tand kecukupan ASI, praktik pemberian ASI eksklusif, dan faktor keberhasilan pemberian ASI eksklusif, seperti paritas, jenis persalinan, riwayat pemberian asupan pada anak yang sebelumnya, IMD, dukungan petugas kesehatan dan keluarga. Pengukuran variabel menggunakan kuesioner yang sahih dan andal. Penghasilan dikategorikan sangat tingei jika $\geq R p 3.500 .00$, tinggi Rp2.500.000-3.500.000 dan rendah jika $<$ Rp2.500.000. Pendidikan dasa merupakan SD dan SLTP sederajat menengah (SLTA), dan tinggi (perguruan tinggi).

Data yang diambil tersebut dimasukkan ke dalam Duan ke dala dilak malisis muriat dilatukan meggunan regresi

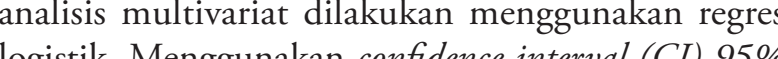

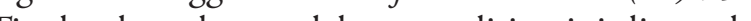
bila $\mathrm{p}<0,05$.

\section{Hasi}

Subjek penelitian didapatkan 82 orang yang memenuh kriteria inklusi. Berdasarkan Tabel 1 didapatkan bahw sebagian besar responden, yaitu 50 (61\%) berhasi memberikan ASI eksklusif. Sejumlah $32(39 \%)$ responden yang tidak memberikan ASI eksklusif, sebagian besar disebabkan karena alasan khawati ASI saja tidak mencukupi kebutuhan bayi. Alasa terbanyak kedua $9(28,1 \%)$ responden karena ibu repot bekerja. Kebanyakan dar responden yang tidak

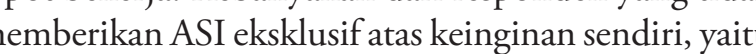
$25(78,1 \%)$ responden

Hasil analisis bivariat antara faktor pendukung pada Tabel 2

Pada Tabel 3 tertera bahwa ibu yang berusia 25-30 tahun memiliki peluang keberhasilan AS eksklusif 16 kali lebih besar jika dibandingkan dengan yang berusia $>30$ tahun. Ibu yang tidak bekerja memiliki peluang keberhasilan ASI eksklusif 24 kali lebih besar dibandingkan dengan yan bekerja. Ibu yang berpendidikan tingoi berpeluang keberhasilan ASI eksklusif 21 kali lebih besar dibandingan dengan yang berpendidikan besar bu yang memiliki pengalonan ketan rendah.

\begin{tabular}{|c|c|c|c|c|c|}
\hline \multirow[t]{2}{*}{ Variabel } & \multicolumn{2}{|c|}{ ASI eksklusif } & \multicolumn{2}{|c|}{$\begin{array}{l}\text { Non ASI } \\
\text { eksklusif }\end{array}$} & \\
\hline & $\mathrm{N}$ & $\%$ & $\mathrm{~N}$ & $\%$ & \\
\hline \multicolumn{6}{|l|}{ Usia (tahun) } \\
\hline$<25$ & 4 & 22,2 & 14 & 77,8 & \multirow{3}{*}{$<0, c$} \\
\hline $25-30$ & 28 & 80 & 7 & 20 & \\
\hline$>30$ & 18 & 62,1 & 11 & 37,9 & \\
\hline \multicolumn{6}{|l|}{ Pekerjaan } \\
\hline Tidak & 39 & 65 & 21 & 35 & \multirow[t]{2}{*}{0,217} \\
\hline Bekerja & 11 & 50 & 11 & 50 & \\
\hline \multicolumn{6}{|l|}{ Pendidikan } \\
\hline Dasar & 8 & 50 & 8 & 50 & \multirow{3}{*}{0,089} \\
\hline Meneng & 23 & 54,8 & 19 & 45,2 & \\
\hline Tinggi & 19 & 79,2 & 5 & 20,8 & \\
\hline \multicolumn{6}{|l|}{ Paritas } \\
\hline Primip & 20 & 55,6 & 16 & 44,4 & \multirow[t]{2}{*}{0,217} \\
\hline Multip. & 30 & 65,2 & 16 & 34,8 & \\
\hline \multicolumn{6}{|l|}{ Jenis persalinan } \\
\hline Normal & 26 & 61,9 & 16 & 38,1 & \multirow{2}{*}{1,000} \\
\hline SC & 24 & 60 & 16 & 40 & \\
\hline \multicolumn{6}{|c|}{ Penghasilan keluarga } \\
\hline Sangat tinggi & 13 & 65 & 7 & 35 & \multirow{3}{*}{0,228} \\
\hline Tinggi & 24 & 53,3 & 21 & 46,7 & \\
\hline Rendah & 13 & 76,5 & 4 & 23,5 & \\
\hline \multicolumn{6}{|c|}{ Riwayat ASI eksklusif (AE) } \\
\hline $\mathrm{AE}$ & 26 & 87,9 & 3 & 50 & \multirow[t]{2}{*}{$<0,001$} \\
\hline Non & 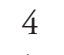 & 23,5 & 13 & 45,2 & \\
\hline \multicolumn{6}{|c|}{ Inisiasi menyusu dini (IMD) } \\
\hline IMD & 32 & 66,7 & 16 & 33,3 & \multirow[t]{2}{*}{0,209} \\
\hline Tidak IMD & 18 & 52,9 & 16 & 47,1 & \\
\hline \multicolumn{6}{|c|}{ tugas kesehatan } \\
\hline Ya & 45 & 60 & 30 & 40 & \multirow[t]{2}{*}{700} \\
\hline Tid & & 71,4 & & 28,6 & \\
\hline \multicolumn{6}{|c|}{ Dukungan keluarga } \\
\hline Ya & 41 & 61,2 & 26 & 38,8 & \multirow[t]{2}{*}{0,932} \\
\hline Tidak & 9 & 60 & 6 & 40 & \\
\hline \multicolumn{6}{|c|}{ Pengetahuan tanda kecukupan ASI } \\
\hline Kurang & 2 & 50 & 2 & 50 & \multirow{3}{*}{0,598} \\
\hline Cukup & 6 & 50 & 6 & 50 & \\
\hline Baik & 42 & 63,6 & 24 & 36,4 & \\
\hline
\end{tabular}

ASI eksklusif pada anak yang terakhir 10 kali lebih besar dibandingkan dengan yang tidak memiliki riwayat keberhasilan ASI eksklusif.

Analisis multivariat yang digunakan adalah regresi logistik backward likelihood ratio. Berdasarkan hasil uji regresi logistik pada tabel X didapatkan dari enam
Tabel 2. Hasil analisis bivariat faktor pemudah, pendukung, dan pendorong

\begin{tabular}{|c|c|c|}
\hline Karakteristik & $\begin{array}{l}\text { Frekuensi } \\
\text { (n) }\end{array}$ & $\begin{array}{c}\text { Persentase } \\
(\%)\end{array}$ \\
\hline \multicolumn{3}{|l|}{ Usia (tahun) } \\
\hline$<25$ & 18 & 22 \\
\hline $25-30$ & 35 & 42,7 \\
\hline$>30$ & 29 & 35,4 \\
\hline \multicolumn{3}{|l|}{ Pekerjaan } \\
\hline Tidak bekerja & 60 & 73,2 \\
\hline \multicolumn{3}{|l|}{ Pendidikan } \\
\hline Dasar & 16 & 19,5 \\
\hline Menengah & 42 & 51,2 \\
\hline Tinggi ${ }^{\circ}$ & 24 & 29,3 \\
\hline \multicolumn{3}{|l|}{ 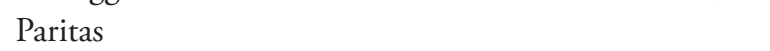 } \\
\hline Multipara & 46 & 56,1 \\
\hline \multicolumn{3}{|l|}{ Jenis persalinan } \\
\hline Normal & 42 & 51,2 \\
\hline \multicolumn{3}{|c|}{ Penghasilan keluarga } \\
\hline Sangat tinggi & 20 & 24,4 \\
\hline Tinggi & 45 & 54,9 \\
\hline Rendah & 17 & 20,7 \\
\hline \multicolumn{3}{|c|}{ Inisiasi menyusu dini (IMD) } \\
\hline Dilakukan IMD & 48 & 58,5 \\
\hline \multicolumn{3}{|l|}{ Pemberian asupan } \\
\hline ASI eksklusif & 50 & 61 \\
\hline \multicolumn{3}{|l|}{ Paparan media ASI } \\
\hline Pernah & 75 & 91,5 \\
\hline \multicolumn{3}{|c|}{ Paparan media susu formula } \\
\hline Pernah & 82 & 100 \\
\hline \multicolumn{3}{|c|}{ Pengetahuan tanda kecukupan ASI } \\
\hline Baik & 66 & 80,5 \\
\hline Cukup & 12 & 14,6 \\
\hline Kurang & 4 & 4,9 \\
\hline
\end{tabular}

variabel yang menjadi kandidat analisis multivariat, yaitu variabel yang memilki nilai $p<0,25$.

\section{Pembahasan}

Peneliti mendapatkan angka proporsi ASI eksklusif 50 (61\%) ibu. Pada Puskesmas Manukan Kulon, 26 dari $41(63,4 \%)$ ibu memberikan ASI eksklusif, angka tersebut meningkat dibandingkan data di Puskesmas yang sama pada profil kesehatan Surabaya 2016, yaitu $40,91 \%$. Hal ini teriadi karena data profil kesehatan 
Tabel 3. Hasil analisis multivariar

Variabel

\begin{tabular}{lllll} 
Slope & Nilai $\mathrm{P}$ & OR & \multicolumn{2}{c}{ IK 95\% } \\
\cline { 4 - 5 } & & & Batas bawah & Batas atas \\
\hline 2,775 & 0,020 & 16,042 & 1,562 & 164,721 \\
3,180 & 0,003 & 24,048 & 2,882 & 200,657 \\
3,041 & 0,030 & 20,930 & 1,334 & 328,387 \\
2,308 & 0,032 & 10,054 & 1,216 & 83,131
\end{tabular}

Usia ibu (25-30 tahun)

Pekerjaan (tidak bekerja)

Pendidikan terakhir (tinggi)

Riwayat pemberian asupan (ASI eksklusif)

$-2,824 \quad 0,032$

tersebut rilis pada tahun 2016, sedangkan penelitian dilakukan pada tahun 2018 sehingga pengembanga program sebagai upaya peningkata
eksklusif mungkin sudah dilakukan

Sebagian besar ibu, yaitu $32(39 \%)$ ibu gagal memberikan ASI eksklusif dengan alasan thawair bahwa pemberian ASI saja tidak mencukupi keburatir bayi. Penelitian seble bayi. Pentich

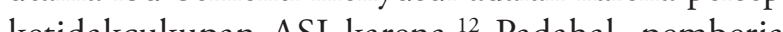

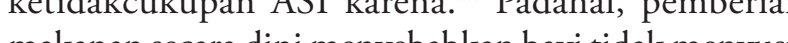
makan secara adekuat se

Peneliti mendapatkan bahwa ketidakcukupan ASI menurut anggapan ibu karena bayi berjenis kelami laki-laki, bayi kembar, dan terlihat rewel setelah menyusu. Menurut lkatan Dokter Anak Indonesia (IDAI) tahun 2013 bahwa tidak ada perbedaan jumlah kebutuhan ASI pada bayi laki-laki atau perempuan. ${ }^{\prime}$ Jika interaksi antara rangsangan mekanik, saraf, da hormon terjadi maka ASI dapat diproduksi sesua kebutuhan bayi. ${ }^{5}$ Pada bayi kembar, jika ibu memiliki pengetahuan yang cukup, mendapat dukungan dar petugas kesehatan, dan sabar maka bayi multipe tetap terpenuhi kebutuhannya. ${ }^{14}$ Sementara bayi yang terlihat rewel atau menangis belum tentu karena sedang lapar. ${ }^{15}$ Bisa jadi popok bayi basah, kepanasan, atau bosan.

Alasan terbanyak kedua ibu tidak memberika ASI eksklusif yaitu tidak ada waktu karena bekerja. Penelitian sebelumnya melaporkan bahwa Ibu yang bekerja dihubungkan dengan tidak adanya waktu untuk menyusui bayi secara intens, cuti yang diberikan perusahaan maskimal dua bulan, serta dihubungkan dengan jarak antara rumah dan tempat bekerja.

Sebagian besar ibu yang tidak memberikan ASI eksklusif adalah atas keinginannya sendiri. $\mathrm{Ha}$ tersebut sejalan dengan penelitian sebelumnya bahwa pengambilan keputusan mengenai asupan yang diberikan pada bayi ada pada ibu sendiri, pengaruh bu sangat besar dalam mengambil keputusan untuk memberikan ASI eksklusif . $^{18}$

Semua ibu pernah terpapar iklan Susu formula, baik melalui media elektronik maupun cetak, tetapi tidak semua ibu $(91,5 \%)$ pernah melihat iklan mengen ASI. Hasil penelition ini menunjukk peningen ASI. Has pe A perna bu mengangga 列 a ${ }^{20}$ iklo susu fo Ahmad, iklan susu formula dapat memberikan efek pada ibu yang berpendidikan rendah da berpengetah ina kurang. Dipentakannya pemberdayaan kelompok ibu yang rentan terhadap pengaruh negat

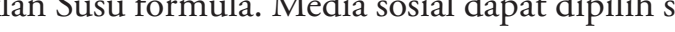
atry point untuk menyusun kampanye ASI

Terdapat hubungan antara usia ibu dengan keberhasilan pemberian ASI eksklusif. Usia ibu yang ideal untuk bereproduksi adalah 20-30 tahun pada usia tersebut ibu memiliki kemampuan laktasi yan baik daripada ibu yang berusia lebih dari 30 tahun. ${ }^{2}$ lbu yang berusia 24-28 tahun kebanyakan berhasi memberikan ASI eksklusif dibandingkan dengan ibu yang berusia 29-33 tahun.

Riwayat keberhasilan ASI eksklusif pada anak sebelumnya berhubungan dengan keberhasilan ASI eksklusif pada anak terakhir. Pengalaman tersebut merupakan sumber kepercayaan diri yang berasal dari pengalaman nyataKegagalan ibu memberikan AS eksklusif sebelumnya akan menurunkan peluan keberhasilan pemberian ASI eksklusif pada anak berikutnya. ${ }^{33}$ Dengan demikian, perlu dilakukan evaluasi terhadap masalah dalam proses menyusu anak yang sebelumnya. ${ }^{33}$

Pengetahuan ibu tentang tanda kecukupan ASI tidak berhubungan dengan pemberian ASI eksklusif. Pengetahuan bukan faktor yang memengaruhi adany persepsi ketidakcukupan ASI dan keberhasilan ASI eksklusif. Hasil penelitian ini sejalan dengan penelitian sebelumnya yang melaporkan bahwa pengetahuan ib tidak berhubungan dengan pemberian ASI eksklusif. Faktor pendorong lain yang memengaruhi pemberian ASI eksklusif adalah dukungan tenaga kesehatan penolong persalinan. ${ }^{20}$ Keberhasilan pemberian AS eksklusif berhubungan dengan pelaksanaan manajemen laktasi oleh petugas penolong persalinan.

Empat faktor yang berhubungan dengan ASI eksklusif, yaitu usia ibu, pekerjaan, pendidikan terakhir dan riwayat pemberian asupan pada anak sebelumnya. Ibu dengan riwayat keberhasilan ASI eksklusif berpeluang berhasil lebih besar untuk

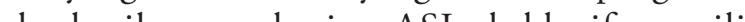
kepercayaan diri yang baik. ${ }^{30}$

Kegagalan sejumlah ibu yang memiliki pengalaman keberhasilan ASI eksklusif pada anak yang terakhir karena ibu bekerja. Tidak adanya dukungan $d$ lingkungan kerja dapat mempersulit ibu untuk memberikan ASI eksklusif. Ibu yang bekerja sulit memberikan ASI eksklusif karena waktu yang sedikit. Dukungan secara personal pada ibu yang bekerja dibutuhkan untuk meningkatkan motivasi dala pemberian ASI.

Peneliti mendapatkan hubungan antara pekerjaa bu dengan keberhasilan pemberian ASI eksklusi lbu yang tidak bekerja memiliki peluang keberhasilan ASI eksklusif yang lebih besar jika dibandingkan ib yang bekerja. Penelitian sebelumnya melaporkan bahwa pekerjaan ibu dihubungkan dengan waktu menyusui yang kurang dan kebijakan lingkungan kerja. Penyediaan fasilitas berupa ruangan menyusui, tempat penyimpanan ASI, dan alat memerah ASI dapat meningkatkan peluang keberhasilan pemberian ASI eksklusif. $26-27$.

Pendidikan terakhir berhubungan dengan kebe hasilan pemberian ASI eksklusif. Ibu yang berpendidikan tinggi (perguruan tinggi) memiliki peluang keberhasilan ASI eksklusif yang lebih besar jika dibandingkan dengan ibu yang berpendidikan rendah (SD dan SLTP sederajat). Hibstu dkk ${ }^{28}$ melaporkan bahwa ibu yang berpendidikan tinggi akan lebih mampu mengurus diri dan bayinya jika dibandingkan dengan ibu yang berpendidikan rendah. Ibu yang berpendidikan tingoi memiliki kesanpatan yntuk mengakses pengetahuan yang lebih luas sehingga ibu lebih yakin terhadap yang ia pahami.
Ibu yang berpendidikan tinggi berani mengungkapkan keinginannya untuk IMD dan berpesan pada petugas kesehatan untuk tidak memberikan susu formula untuk bayinya di tempat persalinan. ${ }^{20}$ Pemberian informasi mengenai ASI dapat diberikan pada ibu yang berpendidikan tinggi, agar kemudian kelompok ibu tersebut menyebarkan pengetahuannya pada ibu yang lainnya. ${ }^{29}$ Hubungan pendidikan dengan keberhasilan pemberian ASI eksklusif dimediasi melalui interaksi dengan beberapa faktor sosial, seperti struktur kelurga dan dukungan sosial, norma teptang makanan alami atau buatan, kondisi ibu yan bekerja intervensi pros sakit.

Ibu yang berusia 25-30 tahun memiliki peluang keberhasilan ASI eksklusif yang lebih besar jika dibandingkan dengan ibu yang berusia $>30$ tahun. Ibu yang berusia lebih tua dan memiliki pengetahuan yang aik memiliki tingkat keberhasilan pemberian ASI eksklusif yang lebih besar. Usia ibu dapat memengaruhi keberhasilan pemberian ASI eksklusif jika diimbangi dengan support system yang baik. ${ }^{8}$

Upaya dalam meningkatkan peluang keberhasilan ASI eksklusif dapat dilakukan dengan mempertimbangkan faktor pendidikan ${ }^{10}$ kemudian menilai faktor sosial lain yang memengaruhi dan melakukan intervensi sesuai kondisi tersebut. ${ }^{22}$ Peningkatan efikasi diri menjadi target promosi dan persiapan menyusui ASI eksklusif. Ibu yang tidak memiliki kepercayaan bahwa produksi ASI-nya cukup dapat mengurangi keberhasilan pemberian ASI eksklusif sekitar 98\%.

\section{Kesimpulan}

Proporsi ASI eksklusif bayi usia 6-11 bulan di Puskesmas Simomulyo dan Manukan Kulon Surabaya adala $61 \%$. Ibu yang memiliki pengalaman keberhasilan ASI eksklusif berusia antara 25-30 tahun, tidak bekerja dan berpendidikan tinggi berhubungan dengan peningkatan peluang keberhasilan ASI eksklusif.

\section{Daftar pustaka}

WHO. The optimal duration of exclusive breasffeeding report Whert consultation. Geneva. Switzerland: WHO 28-30 March 2001. 
2. Kramer MS, Ritsuko K. Optimal duration of exclusive breastfeeding. Cochrane Library Syst Rev 2012;15. Diakse pada 24 oktober 2018. Didapat dari: https://www.ncbi.nlm.nih. gov/pubmed/22895934

3. Gibbs BG, Forste R. Socioeconomic status, infant feeding practices and early childhood obesity. Pediatr Obes 2014;9 $135-46$.

4. Yan J, Liu L, Zhu Y, Huang G, Wang PP. The association between breastfeeding and childhood obesity: a meta-analysis. BMC Pub Health 2014; 14:1267-77.

5. Hancox RJ, Stewart AW, Braithwaite I, dkk. Association between breastfeeding and body mass index at age 6-7 years

Victoria CG Bats rurvey. Pediatr Obes 2015;10:283-7. 21st century: epidem, But Mechanisms, and lifteng Lancet 2016;387:475-90.

7. Dinas Kesehatan Kota Surabaya. Profil kesehatan Kota Surabaya. Surabaya: Dinkes Surabaya; 2016.

8. Ogbo FA, Eastwood J, Page A, dkk. Prevalence and determinants of cessation of exclusive breastfeeding in the early postnatal period in Sydney, Australia. Int Breastfeed J 2017:12:16-25.

9. Dwinanda N, Badriul HS, Damayanti RS. Factors affecting exclusive breastfeeding in term infants. Paediatrica Indonesian 2018;58: 25-35.

10. Conde LC, Juan FSR, Maria JTG, Francisco PR, Monic PT, Juan RO. Relationship between level of education an breastfeeding duration depends on social context: breastfeeding trends over a 40-year period in Spain. J Hum Lact 2017;27: 272-8

11. De Jager E, Helen S, Jaclyn B, Lisa A, Kate M. Psychosocial correlates of exclusive breastfeeding: A systematic review. Midwifery 201329: 506-18.

12. Scott A, Marilou S, Britni A, Pearl AM. Breast-feeding perceptions, belief and experiences of marshallese migrants an exploratory study. Pub Health Nutr 2016;19:3007-16.

13. Getnet M, Melkie E. Exclusive breastfeeding and associated factors among mothers in Debre Markos, Northwest Ethiopis a cross-sectional study. Int Breastfeeding J 2015; 10:1 DO 10.1 186/s13006-014-0027-0.

14. IDAI. Menyusui bayi kembar. buku indonesia menyusui. Jakarta: IDAI; 2013.

15. Setjiningsih. Seri gizi klinik ASI petunjuk untuk tenag kesehatan. Jakarta: EGC; 2012.

16. Wijayanti DS. Gambaran persepsi ketidakcukupan ASI (PKA) pada ibu bayi $0-6$ bulan di Puskesmas Pandanaran Kota Semarang, (skripsi). Depok: Program Studi Sarjana Kesehatan Masyarakat Fakultas Kesehatan Masyarakat Universitas Indonesia 2012
17. Wulansari S, Moch. SP. Hubungan kondisi sosial ekonomi keluarga dengan pemberian ASI eksklusif di wilayah ker Puskesmas Tanah Kali Keddinding Surabaya. Buletin Penelitian Sistem Kesehatan 2014;17: 9-15.

18. Kementerian Kesehatan Republik Indonesia. Profil Kesehatan Indonesia 2013. Jakarta: Kementerian Kesehatan Republit Indonesia; 2013.

19. Alamsyah D, Marlenywati, Ruthayana H. Hubungan antara kondisi kesehatan ibu, pelaksanaan IMD, dan iklan susu formula dengan pemberian ASI eksklusif. Jurnal IKESM 2017:131:68-76.

20. Fikawati S, Ahmad S. Penyebab keberhasilan dan kegagala praktik pemberian ASI eksklusif. Jurnal Kesehatan Masyaraka Nasional 2009; 4:120-31

21. Kurniseri AF Pengaruh terapan iklan layanan masyaraka penggunaan media sosial facebook, dukungan keluarg dukungan lingkungan keria terhata dungan keluarg. ibu bekeria memberi ASI elsklusif Jund Iteraks 20165:

2. Maonga AR, Michael J. Mahande, Damian J. Damian, Sia EM. Factors affecting exclusive breastfeeding among women in Muheza District Tanga Northeastern Tanzania: a mix 20:77-8.

3. Kementerian Kesehatan Republik Indonesia. Bayi gendut, luc tapi belum tentu sehat. Pusat Komunikasi Publik Sekretaria

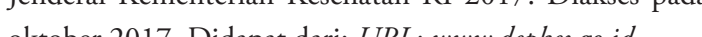

oktober 2017. Didapat dari: URL: wwww.depkes.go.id

24. Wahyuni Y. Determinan persepsi ketidakcukupan ASI (skripsi). Depok. Whalas Keschatan Masyarakat Universits Indonesia; 2012

25. Sonko A Amare W. Prevalence and predictors of exclusive breastfeeding for the first six months of life among women Halaba Special Woreda, Shoutern Nations, Nationalities an Peoples’ Region/SNNPR/. Ethiopisa: a Community Based Cross-sectional Study. Pub Health 2015;73:53.

26. Pernatun C, Eny RA, dan Endah RD. Dukungan tempar bekerja terhadap perilaku pemberian ASI Eksklusif. Jurnal Kebidanan dan Keperawatan 2014; 10: 27-36.

27. Alzaheb RA. Factors influencing exclusive breastfeeding in Tabuk, Saudi Arabia. Clin Med Insights: Pediatrics 2017;11:1-

28. Hibstu DT, Dawit JT, Teshome AA, Fanuel BB. Complementary feeding timing and its predictors among mother's of children aged (6-23) months old in Halaba Kulito Town, Southern Ethiopia. Curr Pediatrics 2018;22:61-68.

29. Velusamy V, Prasanna S. Premkumar, Gagandeep K. Exclusive breastfeeding practices among mothers in urban slum settlements: pooled andysis from three prospective birth cohort studies in South India. Int Breastfeeding J 2017;12:35 . Handayani KD. Hubungan antara hasil pentlaian breasfeeding self-efficacy scale-short form (BSE-SF) dengan infant breastfeeding assesment tool (IBFAT) pada bayi late preter yang mendapat air susu ibu, (penelitian karya ilmiah akhir). Surabaya: Departemen/SMF Ilmu Kesehatan Anak Fakultas Kedokteran Universitas Airlangga RSUD Dr. Soetomo Surabaya 2017.

31. Martini NK, Astuti NPW. Faktor-faktor pendorong ibu dalam memberikan ASI eksklusif di UPT Puskesmas Ii Denpass
Barat. Jurnal Kesehatan Terpadu Maret 2017:12-18.

2. Rosyadi, Dina W. Hubungan antara pengetahuan ibu bekerjas jam kerja dan dukungan tempat kerja dengan keberhasilan ASI eksklusif di wilayah kerja Puskesmas Banyudono I, (skripsi). Surakarta: Fakultas IImu Kesehatan Universitas Muhammadiyah Surakarta 2016.

33. Moraes de OM, and José SCJ. Gestational, perinatal, and postnatal factors that interfere with practice of exclusive breastfeeding by six months after birth. Int Breastfeeding I 2017:12:42. 